\title{
AONDE VAI A EDUCAÇÃO PÚBLICA BRASILEIRA?
}

Luiz Carlos G onçalves Lucas*

ROBERTO LeHER **

Resumo: 0 artigo analisa o cenário da atual greve dos docentes das universidadesfederais. Critica a política educacional brasileirae denuncia o abandono das instituiçõesfederais deensino, com baseem indicadores sobre a transferência de recursos para as universidades. Relaciona esse quadro com um programa mais amplo de reformulação das políticas educacionais em países periféricos, impulsionado por organismos internacionais e examina suas principais conexões com a reforma do Estado iniciada no primeiro governo Fernando $\mathrm{H}$ enrique $\mathrm{C}$ ardoso.

Palavras-chave: U niversidade pública; R eforma do Estado; O rganismos internacionais; Reforma de política educacional.

No entender do ministro da educação, Paulo Renato Souza, não parece haver dúvida: 0 atual modelo definanciamento do ensino superior se esgota em cinco ou seis anos (Folha de S. Paulo, 10/10/2001). A declaração destoa do tom indefectivelmente ufanista da caríssima propaganda do M inistério. E não só destoa como surpreende: não é comum verificar um postulanteà presidência da República admitir que, após longa permanência na chefia de uma área governamental importante, está deixando como legado uma bomba de tempo.

0 que poderia levar à exaustão financeira um sistema educacional público? Concebida a educação como direito, e esse é, sem dúvida, o espírito da Constituição Federal de 1988, cabe ao Estado assegurá-la com recursos do erário, em montante suficiente para garantir o bom funcionamento das instituições. U ma situação análoga à de falência só

\footnotetext{
* Professor do Instituto de Sociologia e Política da U niversidade Federal de Pelotas (RS) e 1은 Vice-Presidente Regional RS do Andes-SN . E-mail: andes.gaucho@terra.com.br

* Professor da Faculdade de Educação da UFRJ/UnB e Presidente do Andes-SN. E-mail: rleher@uol.com.br
} 
poderia ocorrer: a) se o Estado descumprir a sua parte, seja por não proporcionar o necessário suporte financeiro, seja por adotar políticas de expansão dos serviços sem orçamento compatível, e b) se houver desperdício e incapacidade administrativa generalizados e em grau suficiente para provocar um colapso no sistema.

A segunda alternativa pode ser desconsiderada. A pesar de haver inúmeros problemas na administração de algumas instituições, nada indica a existência de uma situaçã̃o de descalabro de proporções nacionais, até porque já nada há para ser desperdiçado. 0 que se vê todo dia é a proliferação de iniciativas - nem sempre recomendáveis, é verdade - para conseguir fechar as contas e manter as universidades vivas em um cenário de miséria.

Resta a primeira alternativa. 0 s problemas futuros, que o ministro tardiamente reconhece, não são, aliás, mais que a conseqüência evidente de uma política cujos efeitos desastrosos já são hoje notórios. Ao contrário do que pretendem mostrar as fantasiosas estatísticas do $M E C$, os recursos destinados às Instituições Federais de Ensino Superior (IFES) têm seguido uma trajetória descendente, ao mesmo tempo em que não cessa de crescer o número de estudantes matriculados, multi plicam-se cursos de graduação e pós-graduação e aumentam as necessidades de material, instalações e equipamentos, em razão do próprio desenvolvimento científico e tecnológico. $\mathrm{N}$ a década de 1970, a folha de pessoal consumia pouco mais de $60 \%$ do total das despesas das IFES. H oje, o próprio M EC informa que absorve cerca de $90 \%$ dos recursos. N ão só isso, paga-se também pessoal com os 10\% restantes. É o caso dos servidores técnicos administrativos terceirizados, além dos professores substitutos que já somam 7,5 mil, justamente os setores em expansão na força de trabalho das IFES. Chegamos, assim, a uma situação em que praticamente só se gasta com pessoal. Se nos ativéssemos apenas a esses percentuais poderíamos inferir que houve ganhos salariais tão el evados que já nada sobra para as outras rubricas. $\mathrm{H}$ ipótese delirante, mas que certamente já deve ter sido levada a sério por algum tecnocrata. $\mathrm{N}$ a realidade, os salários, hoje, atingem os menores níveis de toda a história das IFES. Para recuperar o patamar já baixíssimo - de 1995, conforme o D ieese, seria preciso um reajuste de $75,48 \%$.

O M EC tem, é verdade, implantado uma política de gratificações, com a conseqüência - e certamente o objetivo - de tornar cada vez mais precária a remuneração (hoje, os ven cimentos básicos variam, em média, entre 20 e $28 \%$ do total recebido). Essa política rompe a 
isonomia e estabelece diferenciações não justificadas de tratamento. Além disso, não atinge valores sequer próximos do sugerido pela propaganda governamental.

Estudo do IPEA (C arbucci, 2000) atesta a violenta redução das verbas de manutenção e desenvolvimento das IFES. 0 gasto total com as 39 universidades federais aparentemente se manteve inalterado após 1995. C ontudo, se os valores forem desagregados, o quadro é outro: os gastos com "despesas de capital" (recurso destinado às bibliotecas, insumos, mel horia de instalações etc.) despencaram $80 \%$ : dejá irrisórios R \$ 173 milhões em 1995 para R \$ 31 milhões em 1998. Os recursos das IFES, excluindo aposentados, pensionistas e precatórios, despencaram de já modestíssimos R \$ 4,7 bilhões (1995) para R \$ 3,6 bilhões (1999). Ademais, a despeito do protocolo proposto pela Associação N acional dos Dirigentes das IFES (Andifes) em 1998, comprometendo as universidades com o crescimento de $10 \%$ ao ano das vagas discentes de graduação e pós-graduação, o M EC não cumpriu a sua parte - ampliar os recursos de manutenção na mesma taxa, além de efetivar no quadro oito mil docentes. Em síntese, paga-se mal, não se recompõe a força de trabalho, não se investe nem se garante 0 mínimo necessário para custeio, induz-se à expansão do sistema e depois - heureca - constata-se que estamos em situação préfalimentar.

Como evitar essa morte anunciada? A receita que nos é sugerida pelo ministro é muito simples: mais uma vez, alterar a Constituição (ou, quem sabe, simplesmente ignorá-la?) e cobrar anuidades. Se o fizermos, estará salva a educação nacional. 0 governo poderá confortavelmente continuar a sustentar os infalíveis beneficiários de suas eternas prioridades e desvencilhar-se, finalmente, de qualquer compromisso com instituições universitárias que, sob o olhar míope das elites brasileiras, tornaram-se incômodas. $\mathrm{N}$ ão cumprem muito bem o papel de reprodução ideológica, nem oferecem habilitações tão diretamente acopladas a necessi dades efêmeras do mercado quanto Ihes parece desejável. Teimam em produzir conhecimento, quando poderiam contentar-se em propagar o que nos chega pronto e com a etiqueta do primeiro mundo (Lander, 2001). Formam um número crescente de desempregados com escolaridade elevada que, apesar de representar uma fração diminuta da população brasileira, tendem a exceder não só 0 estritamente exigido pelo processo de acumulação, como também as dimensões necessárias à função tradicional de exército social de reserva. Tornou-se uma universidade cara, para o pouco que se espera dela. 


\section{O Ensino Superior segue as prioridades do Banco M undial}

O bstinado em implementar as políticas de ajuste e privatização determinadas pelo $\mathrm{FM} \mathrm{I}$ e o Banco M undial, o ministro da educação assevera que: "a ênfase no ensino universitário foi característica de um modelo de desenvolvimento auto-sustentado que demandava criar pesquisa e tecnologias próprias [...] hoje este modelo está em agonia terminal" (Exame, 10/6/1996).

A nova geração de economistas que assumiram o Banco $M$ undial em 1980, indicados por Reagan, como Anne Krueguer e G. Psacharopoulos, estabeleceu que, no caso dos países periféricos, o ensino fundamental oferece uma taxa de retorno muito maior do que a do ensino superior e a da educação tecnológica. D esde então, os governantes latino-americanos afinados com o Consenso de W ashington excluíram a universidade de suas prioridades. Q uando indagado sobre a primazia de sua política educacional, o presidente Fernando H enrique Cardoso respondeu: "a universalização do ensino primário e freagem do crescimento da universidade federal" (Archard \& Flores, 1997, p. 85).

I merso na ideologia da globalização, o ministro Paulo Renato argumenta que "as associações e joint ventures se encarregam de prover as empresas de países como o Brasil do know-how que necessitam". Parece esquecer que $99 \%$ das patentes pertencem a corporações multinacionais dos países do G -7; que os custos da propriedade intelectual inviabilizam 0 acesso da população a direitos essenciais como a saúde e que, em um contexto no qual o conhecimento científico dobra a cada cinco anos, os países, quando submetidos ao apartheid educacional planetário, ficam relegados à condição neocolonial (Leher, 2001).

Ao mesmo tempo em que o ensino superior público é exaurido de todos os val ores necessários à sua manutenção, a oferta de vagas no ensino superior pelo setor privado é vigorosamente apoiada e subsidiada pelo Poder Público, sem qualquer mecanismo de controle social. T ratase, mais uma vez, de submissão a recomendações do Banco M undial, cumpridas em grande número de países periféricos, com o argumento de que a educação privada é mais barata, cabendo, portanto, fomentarIhe o desenvolvimento, como imperativo de racionalidade econômica. A asfixia financeira do setor público é, em si mesma, importante incentivo para a verdadeira explosão de estabelecimentos particulares. Assim é que proliferam, na atual gestão do M EC , cursos irregularmente abertos fora da sede de universidades que, a rigor, e em respeito ao disposto no Art. 207 da Constituição F ederal, não poderiam ostentar 
estetítulo. 0 setor privado caracteriza-se, salvo al gumas poucas universidades dignas desse nome, por uma infinidade de fabriquetas de diploma, subsidiadas segundo sua capacidade de influência junto ao governo. D e fato, "o C onselho $\mathrm{N}$ acional de Educação, que substituiu 0 antigo Conselho Federal de Educação (CFE) entrou em crise, que começou com a demissão do filósofo ] osé Arthur Gianotti [...] em protesto contra a criação de uma universidade privada sem requisitos mínimos [...]". T ambém Eunice D uhram, importante colaboradora dos governos Collor e FH C "criticou fortemente o M EC e faz uma grave acusação: tem havido um crescimento desmesurado do sistema privado. Esse movimento está sendo governado pelo mercado, pelo processo do lucro, e está ameaçando a credibilidade do sistema de ensino superior no Brasil" (Trindade, 2001, p. 31). Assim, em nítido contraste com a redução do financiamento das Federais, em apenas dois anos o BN D ES liberou $\mathrm{R} \$ 750$ milhões para as instituições privadas.

$N$ ão se costuma explicitar que a conseqüência direta dessa política seria a generalização de um modelo de baixa qualidade de ensino, mas se reitera uma justificativa ética: 0 ensino superior público é privilégio dos ricos e não se deve custeá-lo com recursos tributários extraídos de toda a população. Talvez se devesse pagar direitos autorais ao diabo. Q uando Karl M arx, na Crítica ao Programa de G otha, fez considerações desse tipo em relação ao ensino superior gratuito oferecido em alguns estados americanos, não percebeu o potencial, em futuro então remoto, da educação pública superior como instrumento importante de formação integral das classes trabal hadoras, mas estava correto quanto aos efeitos financeiros da política educacional de sua época. H oje, mesmo num país marcado pela desigualdade, como o Brasil, os dados existentes revelam que mudou o perfil do corpo discente e que as universidades federais não são privilégio de estudantes oriundos das elites.

As considerações de justiça distributiva a favor da escola privada ou paga, formuladas por el ites adestradas na arte de travestir o interesse próprio com a roupagem do bem comum e de agravar a concentração de renda, não são mais que hipocrisia banal. Colidem com os dados referentes à situação socioeconômica dos alunos das universidades públicas. D esconhecem que a educação superior não pode, em nenhum lugar do mundo, ser custeada em proporção significativa pelos estudantes. Q ue, mesmo no $\mathrm{C}$ hile, freqüentemente citado como exemplo, essa proporção não passa de $30 \%$ e é obtida graças à perda de qualidade e à elitização do acesso. E têm sempre a função não declarada de escamotear a análise dos fluxos distributivos através do Estado, preservando 
outros campos onde seria mais pertinente: política fundiária, financiamento de latifundiários, PROER, dívida pública, política tributária, subsídios a privatizações e a mega-corporações.

Q uando o ministro da Educação prevê o esgotamento do financiamento das universidades em decorrência de sua expansão, baseia-se apenas num truísmo: é óbvio que os custos são crescentes. $M$ as perde a oportunidade de discutir as razões pelas quais não se pode prever 0 aumento da cobertura orçamentária. T alvez tome como fatalidade natural a perpetuidade da atual trajetória de abandono, que nega, ao fazer marketing pessoal, mas projeta para o futuro ao sugerir a cobrança de anuidades.

H á, no raciocínio do ministro - ou, mais precisamente, em suas lacunas - , a repetição de um traço comum a todo o discurso governamental, ao de seus mentores externos, ao dos intelectuais e tecnocratas da direita, ao da grande mídia: a recusa sistemática à análise crítica das prioridades na aplicação dos recursos do Estado e em sua extração tributária.

Como essas prioridades, em tempos de ajuste neoliberal, não costumam contemplar a área social, os responsáveis pelas políticas públicas nessa área são permanentemente confrontados com um dilema: enfrentar os setores que real mente têm poder ou renunciar a qualquer disputa mais efetiva por parcelas do orçamento que Ihes permitam desempenhar a contento suas tarefas.

$\mathrm{N}$ esse sentido, a permanência à frente do M EC de um tecnocrata sem base própria de poder é garantia de submissão e de inexistência de disputas internas sérias. Por outro lado, gera grandes dificuldades no relacionamento com as IFES e os que nel as trabalham. D ificuldades certamente exacerbadas pela personali dade do ministro, que se especializou em emitir declarações infelizes, multiplicar atritos e destruir a aceitação que o governo FH C já teve junto a uma parcela não desprezível do corpo docente. T ecnocrata catapultado à condição de político sem voto ou mandato e acometido de implausíveis aspirações presi denciais, o titular da pasta da Educação precisa desesperadamente continuar no cargo para ter sobrevida política. Entre o mar e o rochedo, não pode contrariar a área econômica, que realmente tem poder. V olta-se com fúria contra os professores em greve, numa estratégia marcada pela combinação pouco recomendável entre servilismo e truculência. Q uem leu o belo estudo de Adorno sobre a personalidade autoritária talvez não se surpreenda. 


\section{Privatização éa alma da política educacional}

A privatização tem sido a alma das políticas educacionais sob FHC. I sso não significa que o governo quer fechar as universidades, nem vendêlas na bolsa de valores, a reação seria forte, mas privatizálas a partir de dentro, enredando os professores em sua lógica operacional, por meio de sufocante arrocho salarial, deslocando, deste modo, a universidade para a esfera privada como um serviço voltado para 0 mercado. 0 neoliberalismo subordina a universidade ao modo capitalista de produzir, sentir e pensar de forma insidiosa. Conjuga medidas estabelecidas pelos centros de decisão governamental com a difusão de modus operandi internos em consonância com sua lógica operacional. É uma forma perversa, pois aparece como natural einexorável, contando com a conivência de parcel as importantes da comunidade, como vimos na intervenção do MEC na UFRJ. O utro aspecto do processo de privatização não declarada é a velocidade em que as próprias IFES estão sendo transformadas em espólio disputado por interesses privados internos, sobretudo por meio das fundações de apoio, em processos normalmente eivados de ilegalidades, sob a complacência governamental. ${ }^{1}$

Por esses caminhos indiretos tem avançado o processo de destruição da esfera pública, sem que se torne necessário - ou até que seja possível - alterar a natureza jurídica das IFES, para transferi-las à órbita privada. Certo, não há confirmação desse objetivo nos arquivos públicos do MEC. M as seria provavelmente inútil procurar nesses escan inhos burocráticos transbordantes de peças de marketing qual quer documentação consistente a propósito das políticas ali implantadas.

Em áreas mais nobres e intelectualmente valorizadas do governo FH C há textos em abundância. Seguem o estilo sinuoso do ex-ministro Bresser Pereira, que lhes deixou sua marca pessoal inconfundível. N ão falam em privatizar, mas em publicizar as universidades federais. Sob um véu de ambigüidades, de imprecisão conceitual e de referências superficiais a um tema polêmico, como o da área pública não-estatal, descobre-se, depois de percorrer muitos malabarismos verbais, o que, na realidade, isso significa: trata-se de transformar as universidades públicas em organizações sociais, com natureza jurídica de fundações de direito privado.

C abe lembrar que, durante a ditadura, sob a vigência do $D$ ecreto Lei no 200/67, a proliferação de instituições desse tipo foi justamente um dos principais instrumentos que permitiram ao mesmo tempo 0 
crescimento do Estado e a sua captura por interesses privados, sem qualquer controle público. N os últimos momentos do regime, a administração do país constituía um quadro caótico, dominado por práticas de nepotismo, pouco transparente, com relações de trabalho al tamente informais e não isonômicas.

No final da década de 1980, essas fundações foram finalmente submetidas a um processo de racionalização burocrático-legal que permitia pelo menos fiscalizar a aplicação dos recursos que Ihes eram transferidos pela U nião, sempre que se tratassem de organizações instituídas pelo poder público. Para evitar essa conseqüência, tida como indesejável, propõe-se que as novas entidades sejam criadas por pessoas físicas. Ficariam, assim, isentas de praticamente todo controle público. Relacionar-se-iam com o governo por meio de contratos de gestão, firmados diretamente com o primeiro escalão do Executivo. Receberiam recursos em troca do compromisso de executar determinadas tarefas durante certo tempo, após o qual deveriam prestar contas à mesma autoridade com a qual teriam firmado o contrato. Esta decidiria, após avaliação, sobre a conveniência ou não derenová-lo. I sso nos éapresentado como forma de controle desprovida de rigidez burocrática e adequada às necessidades de um novo Estado gestor, que se pretende implantar.

$\mathrm{N}$ a realidade, a proposta não contém quase nada de novo e representa, ao contrário, um retorno a formas antiqüíssimas de administração patrimonialista, cujas origens remontam a práticas de venda de cargos que vigoraram na Europa durante o feudalismo e o absolutismo e, entre nós, no período colonial.

Significa a exacerbação ao extremo da tendência de tratamento das funções públicas como patrimônio privado dos governantes, presente há cinco séculos no cenário brasileiro. D enota uma concepção profundamente autoritária e centralizadora da política de educação superior, ao procurar submetê-la em bloco à vontade unipessoal do ministro. Colide de maneira frontal e inconciliável com qualquer definição minimamente decorosa de autonomia universitária. Procura desobrigar o Estado das responsabilidades de sustentação financeira das IFES e fazer com que o modelo de financiamento do setor privado se estenda, finalmente, à imensa maioria das universidades brasileiras.

U m dos maiores obstáculos à realização desse programa tem sido o Regime Jurídico Ú nico (RJU), norma juridicamente adequada ao serviço público, mas incompatível com a regulamentação do trabalho em organizações privadas. Essa é talvez a principal razão pela 
qual os teóricos da reforma do Estado preconizam a sua substituição gradual pela CLT. Não podem, por impedimento constitucional, simplesmente mudar o regime jurídico do pessoal já admitido, mas podem deixá-lo em um quadro de extinção, ao qual seria dispensado, sem nenhuma dúvida, tratamento discriminatório (Lucas, 2000).

Se, do ponto de vista governamental, o RJU é uma barreira que se deve remover para fazer avançar o processo de privatização, do ponto de vista dos professores e funcionários das IFES, ele se tornou, com todas as suas fal has, uma garantia contra a destruição da universidade pública e a desvalorização total de seu trabalho.

A elaboração legislativa para implantação da dualidade de regimes está, hoje, a meio caminho. Foi alterada a Constituição Federal com a Emenda Constitucional $n-19$, que permite a contratação pela CLT de pessoal para a administração pública, à semelhança do que ocorria durante a ditadura. No início de 2000, publicou-se a Lei no 9962, que disciplina, em linhas gerais, a aplicação do regime cel etista. $M$ as a criação dos empregos depende de leis específicas, aplicáveis a diferentes ramos do aparel ho burocrático. $\mathrm{N}$ o M EC, quase imediatamente após a promulgação da Lei no 9962, criou-se um grupo de trabalho, com essa finalidade. A té hoje, várias minutas de anteprojeto foram feitas. D espertaram sempre a rejeição unânime de docentes e técnicos-administrativos. Essa rejeição foi uma das principais causas da atual greve, em cuja pauta a recomposição dos quadros docentes no Regime Jurídico Ú nico é um dos itens mais importantes.

H oje, o governo já não tem condições de impor a celetização do trabalho nas IFES, e isso constitui, sem nenhuma dúvida, uma das vitórias mais expressivas do movimento docente nos últimos tempos. D escartada a implantação da CLT, rompe-se um elo necessário da cadeia que conduziria à privatização total. Começa-se a desfazer a imbricação entre educação e reforma do Estado, que caracterizou o governo FHC, e que buscou, com mais clareza e intensidade do que em qualquer período anterior de nossa história, subordinar as universidades ao mercado.

Evidentemente, muito do receituário atual é reedição de antigas recomendações. E a política concreta não é nunca a materialização das intenções de qualquer agente isolado, mas produto de uma correlação de forças na qual o movimento docente sempre se fez presente. 
$\mathrm{N}$ os anos 60, sob influência da Aliança para o Progresso, da USAID e de projetos como Camelot, o movimento, por parte dos EU A, no sentido detornar nossas universidades instituiç̧ôes do "mundo livre", era público e notório. Esta presença somente não foi maior porque as considerações educacionais da Aliança para o Progresso rapidamente foram manchadas de sangue. Para garantir os valores do mundo livre, uma onda de gol pes militares foi empreendida na região. D e outra parte, o movimento de contestação às ingerências dos EUA também foi significativo. Assim, os projetos de reforma educacional, como a reforma universitária brasileira (Lei 5540/68), não puderam seguir estritamente as orientações da U SAID , pois isto explicitaria de forma excessiva a presença dos EUA na reforma. Após o escândalo Camelot, os golpes e os acordos dos ministérios com a U SAID, era preciso evitar 0 excesso de exposição, visto que a reação popular contra a ingerência se fortalecia.

N os anos 70, as políticas de difusão do modelo "condizente com o mundo livre" foram muito mais sutis. No lugar de acordos governamentais, foram difundidos programas de cooperação acadêmica com universidades dos EUA. O governo militar brasileiro, empenhado na modernização conservadora, apoiou a expansão do ensino superior. Entretanto, este movimento contraditório fugiu ao controle do poder governamental. No período, houve importante crescimento da pósgraduação e da pesquisa em áreas básicas das ciências da natureza e nas ciências sociais.

N os anos 80, a crise da dívida externa de 1982 expôs a fragilidade do desenvolvimentismo. Sob a influência da ideologia da gl obalização e do pensamento neoliberal, firmou-se, entre os que falam pel o capital, o consenso da inexorabilidade das reformas. E estas idéias foram transpostas para a América Latina com o nome de Consenso de W ashington, por meio de condicionalidades do FMI/Banco M undial. É neste contexto que o Banco M undial se afirma como M inistério M undial da Educação dos Países Periféricos, fonte inspiradora da política de privatização interna da universidade e de propostas visando à perda total de seu caráter público, como os contratos de gestão previstos nos Fundos Setoriais e o retorno do Regime de CLT . N ão são peculiaridade nossa. N a maioria dos Estados da Asia e da América L atina vêm sendo implantadas reformas semel hantes, e o Brasil tem mesmo conseguido resistir razoavelmente. 
No final da década de 1980, com a derrocada da ditadura e 0 fortalecimento dos movimentos populares, foi possível obter, sobretudo durante o processo da Constituinte, algumas mudanças importantes em defesa do caráter público das IFES. Foram relevantes, entre outros pontos, o reconhecimento da autonomia das universidades, a gratuidade, a democracia de gestão, a garantia de tratamento isonômico e a regulamentação estatutária do trabal ho. $\mathrm{N}$ os anos seguintes, com 0 avanço da hegemonia neoliberal, tudo isso foi, de alguma maneira, violado ou objeto de propostas de emenda, bem sucedidas ou não. M as a demolição desse arcabouço institucional não foi completa e a resistência das comunidades - numa fase em que as organizações sindicais no mundo inteiro estiveram em defensiva - impediu a privatização e segmentação totais das IFES, durante um período suficiente para que os efeitos perversos da vaga liberal se tornassem evidentes.

$\mathrm{N}$ o início de seu primeiro governo, Fernando $\mathrm{H}$ enrique chegou a contar com apoio razoável entre professores. Era um acadêmico respeitado, não identificado com a direita tradicional. H oje, a adesão praticamente unânime à atual greve mostra um quadro bem diferente. Esgotou-se a legitimidade governamental, foi barrado o projeto de lei de emprego público, já não há tempo ou condiç̃es de formulação de novas iniciativas a favor do programa do Banco M undial e o movimento docente mostra forte capacidade de mobilização. Prenúncio de uma nova etapa.

Recebido para publicação em novembro de 2001.

N ota

1. D ossiê "Fundações Privadas na U SP". Revista ADU SP, nํ22, março de 2001.

W HERE IS THE BRAZILIAN PUBLIC EDUCATION GOING TO?

Abstract: This paper analizes the bakground of the current teacher's strike in theF ederal institutions of education. Based on resourcetranfer indicators, it criticizes the Brazilian educational policy and reveals its carelessness as for public universities. It also links this setting to a wide program of educational policy reformsin peripheral countriesimpelled by international organizati ons and examines their main connections to the State reform that began under M r. Cardoso'sfirst government.

Key words: Public university; State reform; International policy reform; Educational policy reform. 


\section{Referências bibliográficas}

ARCHARD \& FLORES. Gobernabilidad: Un reportaje de América Latina. M éxico: PN UD/Fondo de Cultura Económica,1997.

CARBU CCI, P.R. Indicações sobre o 0 rçamento das IFES. Textos para D iscussão, Rio de Janeiro: IPEA, ago. 2000, no 752.

LAN DER, E. "Conhecimento para quê? Conhecimento para quem? Reflexões acerca da geopolítica dos saberes hegemônicos." In: GentiLI, P. (0 rg.), U niversidades na penumbra: N eoliberalismo e reestruturação universitária. São Paulo: Cortez, 2001.

LEHER, R. "Projetos e modelos de autonomia e privatização das universidades públicas." In: G EN TILI, P. (O rg.), U niversidadesna penumbra: N eoliberalismo e reestruturação universitária. São Paulo: Cortez, 2001.

LUCAS, L.C. M otivos de sobra para repetir o ajuste liberal. Revista ADU SP, 2000, nำ 21.

TRIN D ADE, H. "As metáforas da crise: $D$ a 'universidade em ruínas' às 'U niversidades na Penumbra' na América Latina". In: GenTILI, P. (O rg.), U niversidadesna penumbra: $N$ eoliberalismo ereestruturação universitária. São Paulo: Cortez, 2001. 